\title{
Spotlight on brodalumab in the treatment of moderate-to-severe plaque psoriasis: design, development, and potential place in therapy
}

This article was published in the following Dove Press journal:

Drug Design, Development and Therapy

7 July 2017

Number of times this article has been viewed

\author{
Michael Roman' \\ Melvin W Chiu ${ }^{2}$ \\ 'David Geffen School of Medicine \\ at UCLA, ${ }^{2}$ Division of Dermatology, \\ David Geffen School of Medicine \\ at UCLA, Los Angeles, CA, USA
}

Correspondence: Melvin W Chiu Division of Dermatology, David Geffen School of Medicine at UCLA, 52-12I Center for the Health Sciences, 10833 Le Conte Avenue, Los Angeles, CA 90095, USA

$\mathrm{Tel}+|31082569|$ |

Email mchiu@mednet.ucla.edu

\begin{abstract}
Brodalumab is a novel fully human immunoglobulin G2 monoclonal antibody that antagonizes the interleukin (IL)-17 pathway by binding with high affinity to human IL-17RA. The role of IL-17A in the pathogenesis of psoriasis, as well as the remarkable effectiveness of IL-17 inhibitors in the treatment of moderate-to-severe plaque psoriasis, is well established. The mechanism of action of brodalumab is unique in that it inhibits the IL-17 receptor compared to the two other currently FDA-approved IL-17 inhibitors, secukinumab and ixekizumab, which inhibit the IL-17A molecule itself. The efficacy of brodalumab in the treatment of moderateto-severe plaque psoriasis has been demonstrated in phase 2 and 3 trials, and subsequently the FDA approved this medication in February 2017. Brodalumab was approved in Japan in July 2016 and approval is pending in Europe. The safety and adverse effects of brodalumab were reviewed across several clinical trials, which, similar to other IL-17 inhibitors, demonstrated increased rates of neutropenia and Candida infections. Brodalumab treatment, similar to ixekizumab and secukinumab, showed no improvement in inflammatory bowel disease patients, and on the contrary, more exacerbations were encountered. Suicidal ideation and behavior events have been reported with brodalumab treatment and are of significant concern. Brodalumab provides another highly effective treatment option for moderate-to-severe plaque psoriasis.
\end{abstract}

Keywords: brodalumab, biologics, IL-17, plaque psoriasis

\section{Introduction}

Psoriasis is a chronic and complex inflammatory disease that presents as erythematous scaly plaques on the skin and occurs in genetically susceptible individuals. Today, it remains a common disease worldwide, affecting $2 \%$ of the Western population and $3.2 \%$ of US adults. ${ }^{1,2}$ Moreover, this disease impacts patient's health-related quality of life and is associated with both social and psychological ramifications. ${ }^{3}$

Medical therapy for psoriasis has classically included topical and systemic treatments such as phototherapy, retinoids, methotrexate, and cyclosporine. However, due to recent developments in the understanding of the pathogenesis of this disease, the treatment paradigm has now shifted toward targeting specific inflammatory pathways. Biologic agents that specifically block the IL-17 pathway have shown promising results with regard to efficacy and safety. 4,5

Brodalumab is a novel fully human immunoglobulin G2 monoclonal antibody that antagonizes the IL-17 pathway by binding with high affinity to human IL-17RA. Both phase 2 and 3 trials showed the efficacy of brodalumab in the treatment of moderateto-severe psoriasis. ${ }^{4,5}$ As a result, the US FDA approved brodalumab, for subcutaneous (SC) use, for the treatment of moderate-to-severe plaque psoriasis on February 16, 
2017. ${ }^{6}$ The first worldwide approval of brodalumab occurred in Japan in July 2016. ${ }^{7}$ Brodalumab is also being considered for approval in Europe, with the European Medicines Agency (EMA) decision to be released in early 2017. In addition, brodalumab has also shown benefit in the treatment of psoriatic arthritis (PsA), rheumatoid arthritis, and asthma. ${ }^{8}$ This study reviews the immunology of the IL-17 pathway, available data regarding the initial design of brodalumab, drug development through clinical trials, and its potential place in the treatment of moderate-to-severe plaque psoriasis.

\section{Design}

\section{Immunology of the IL-I7 pathway}

Psoriatic plaques are the result of a complex series of immunologic events beginning with natural killer cells, macrophages, and dendritic cells (Figure 1). ${ }^{9-11}$ These cells produce multiple cytokines that lead to the production of two important signaling cytokines: IL-12 and IL-23. IL-12 leads to the differentiation of T cells into Th1 cells, whereas IL-23 leads to the differentiation of T cells into Th (T helper) 17 cells. ${ }^{12}$ The Th17 cells, in turn, produce the cytokines IL-17A-F, IL-21, IL-22, and tumor necrosis factor-alpha (TNF- $\alpha){ }^{13}$

Studies have shown that the skin lesions and the blood of psoriasis patients contain increased levels of both Th17 cells and IL-17, and this cytokine correlates with disease severity. After successful treatment of psoriasis, these levels decreased, further supporting the notion that IL-17 plays a central role in the development of psoriatic plaques. ${ }^{12,13}$ IL-17 is involved in neutrophil chemotaxis by activating dendritic cells to release IL-8, CXCL-1, CXCL-3, CXCL-5, and CXCL-6. ${ }^{13,14}$ IL-17 also stimulates fibroblast production of vascular endothelial growth factor, thus leading to angiogenesis and endothelial cell proliferation. ${ }^{15}$

The IL-17 family is composed of six members (A-F). The IL-17A molecule exists as a homodimer of two IL-17A chains or as a heterodimer with IL-17F. In addition, IL-17F, $\mathrm{E}$, and $\mathrm{C}$ exist as individual homodimers. ${ }^{16} \mathrm{IL}-17 \mathrm{~A}$ and IL-17F are the most understood in terms of function, while

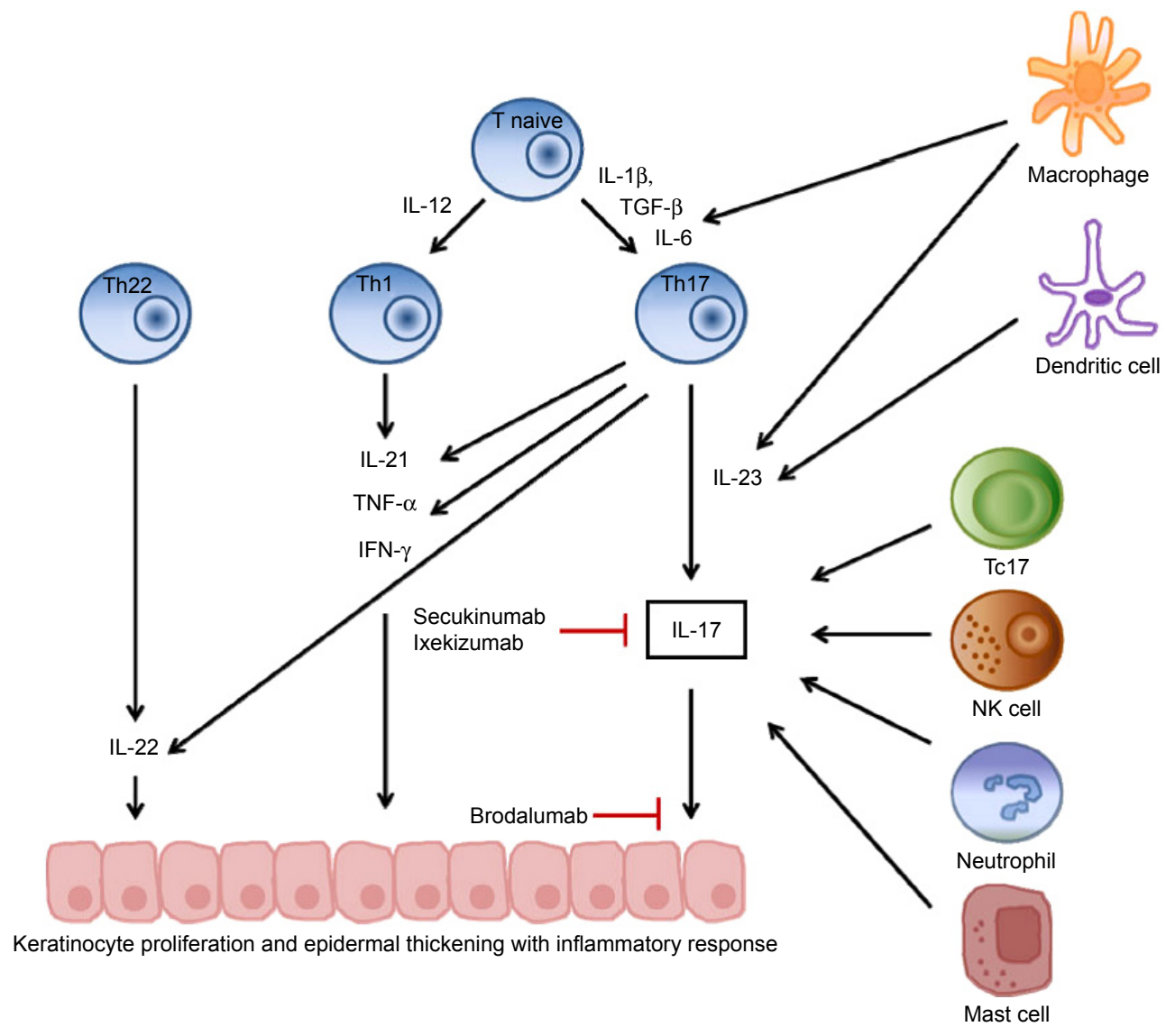

Figure I Interleukin (IL)- I7 in the pathogenesis of psoriasis and targets for brodalumab, secukinumab, and ixekizumab.

Note: Copyright @2014. Dove Medical Press. Reproduced from Lønnberg AS, Zachariae C, Skov L. Targeting of interleukin-I7 in the treatment of psoriasis. Clin Cosmet Investig Dermatol. 20I4;7:25I-259."1

Abbreviations: IFN- $\gamma$, interferon-gamma; NK, natural killer; Tc, cytotoxic T cells; TGF- $\beta$, transforming growth factor-beta; Th, T helper; TNF- $\alpha$, tumor necrosis factoralpha. 
IL-17A is the most influential of the cytokine family. ${ }^{17}$ The role of IL-17A has been well established in the etiology of psoriasis, as well as multiple sclerosis, rheumatoid arthritis, and inflammatory bowel disease (IBD). Moreover, it is involved in innate immune defenses against fungal and bacterial pathogens. ${ }^{13}$

\section{Mechanism of action}

The IL-17 cytokines exert their effects by targeting five cell surface receptors (RA-RE). IL-17RA exists as a heterodimer with IL-17RB, IL-17RC, and IL-17RE. ${ }^{11,17}$ Both IL-17A and IL-17F bind to the IL-17RA/IL-17RC heterodimer. On the other hand, IL-17E (otherwise known as IL-25) binds to the IL-17RA/IL-17RB heterodimer. ${ }^{11}$ Brodalumab is a fully human immunoglobulin G2 monoclonal antibody that binds to IL-17RA, thus blocking the actions of IL-17A, E, and F. ${ }^{18,19}$ In contrast, two other FDA-approved IL-17 antibodies, ixekizumab and secukinumab, target the IL-17A cytokine itself (Figure 2). ${ }^{11}$

Significant gene expression changes and almost complete reversal of the psoriatic phenotype have occurred as a result of IL-17RA antagonism. ${ }^{20}$ Specifically, expression of numerous keratinocyte genes elevated in psoriatic lesional skin, including KRT6A (keratin 6a), IL-1F6 (IL-36a), the chemokine CXCL6, and the antimicrobial peptide gene $S 100 A 7 A$ all decreased within 1 week and returned to nonlesional levels after 2 weeks of treatment with brodalumab. On the other hand, the normalization of expression of T cell-specific genes (CD3E, CD80, CD83, and $I L-4 R$ ) took slightly more time, approaching nonlesional levels after week 6. Analogously, expression of

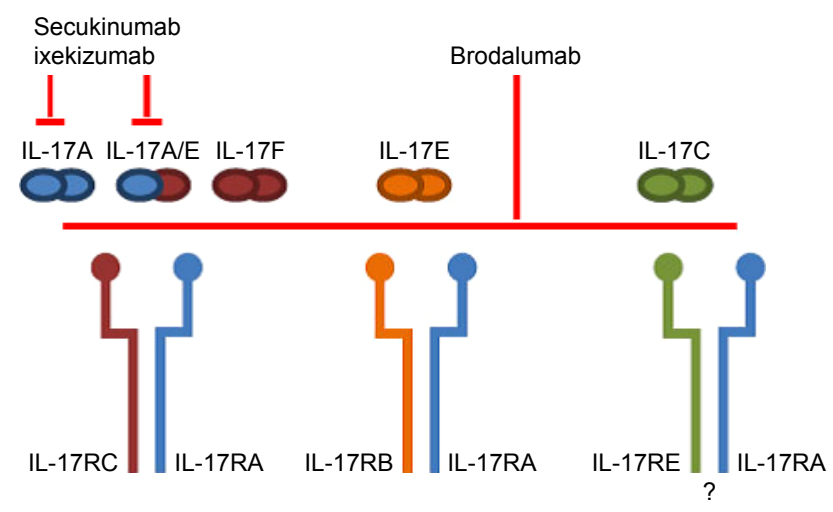

Figure 2 The interleukin (IL)- 17 family ligands and receptors involved when ILI7A is neutralized with secukinumab or ixekizumab or IL-I7RA is blocked with brodalumab.

Notes: There is controversy in the literature concerning the structure of the receptor of IL-I7C. Copyright C2014. Dove Medical Press. Reproduced from Lønnberg AS, Zachariae C, Skov L. Targeting of interleukin- 17 in the treatment of psoriasis. Clin Cosmet Investig Dermatol. 2014;7:25I-259." psoriasis-related inflammatory cytokines $I L-17 C, I L-12 A$, and $I L-23 A$ decreased rapidly within 2 weeks of brodalumab treatment, whereas expression of other more downstream inflammatory cytokine genes $(I L-17 A, I L-17 F, I L-22$, and IFN-gamma) did not decrease toward nonlesional levels until week 6. From a histological perspective, this gene expression normalization was followed by rapidly reduced keratinocyte hyperplasia and a subsequent decrease in the number of infiltrating leukocytes. ${ }^{21}$

\section{Drug development Pharmacokinetics (PK) and pharmacodynamics (PD)}

Using a phase 1 single-dose study design, Salinger et $\mathrm{al}^{22}$ were the first to characterize the PK and PD of brodalumab. A total of 57 healthy subjects and 25 moderate-to-severe psoriasis patients were randomized to receive single placebo or brodalumab doses (7-700 mg) via SC and intravenous (IV) routes of administration. A PK-PD model based on the trial results was developed to establish the relationship between brodalumab exposure and Psoriasis Area and Severity Index (PASI) responses. Both linear and nonlinear elimination pathways best characterized brodalumab PK properties.

PK model estimates of brodalumab volume of distribution $(\mathrm{V}=3.9 \mathrm{~L}$, standard error $[\mathrm{SE}]: 5.1 \%)$ and clearance were consistent with those observed in human subjects treated with other monoclonal antibodies. The estimated bioavailability, peripheral volume, and intercompartmental clearance of brodalumab were 57.6\% (SE: 8.9\%), 2.89 L, and $1.01 \mathrm{~L} / \mathrm{d}$, respectively. In addition, the results of PK-PD (PASI) model estimated brodalumab's maximum inhibition of PASI formation $\left(\mathrm{I}_{\max }\right)$ to be fixed at 1 . As such, at large doses, brodalumab could theoretically achieve full $100 \%$ reduction in PASI. Finally, brodalumab's estimated concentration of half-maximal inhibition $\left(\mathrm{IC}_{50}\right)$ was $2.86 \mathrm{mg} / \mathrm{mL}(\mathrm{SE}: 50 \%)$, and the endogenous psoriatic plaque formation rate was 0.862 (SE: 40\%) PASI units/d, consistent with literature precedent. Although small sample size and single dosing limited the study results, this model set the groundwork for brodalumab dosing in subsequent phase 2 studies. ${ }^{22}$

Endres et al in 2014, constructed a population PK model from phase $1 \mathrm{a}$ and phase 2 clinical studies. ${ }^{23}$ Brodalumab was estimated to have a low volume of distribution and slow clearance, as would be expected with large hydrophilic antibodies with limited tissue penetration. Different scenarios were simulated based on the PK model to assess the impact of covariates such as total body weight (TBW), age, and 
diagnosis of psoriasis on area under the concentration-time curve $\left(\mathrm{AUC}_{\mathrm{ss}}\right)$ and steady-state maximum serum brodalumab concentrations $\left(\mathrm{C}_{\text {max,ss }}\right)$. The authors found that the effects of age and diagnosis on PK were not clinically significant. For doses between 140 and 210 mg, the $\mathrm{AUC}_{\mathrm{ss}}$ was twofold higher in patients weighing $<75 \mathrm{~kg}$ compared to heavier subjects. Moreover, there was a positive correlation between TBW and mean population clearance rates. ${ }^{23}$

A phase $1 \mathrm{~b}$ study by Martin et $\mathrm{al}^{24}$ assessed the safety, PK, and early clinical response of brodalumab in patients with methotrexate-resistant rheumatoid arthritis. This study was double blind, including ten patients in the placebo group (6 SC and $4 \mathrm{IV}$ ) and 30 patients in the brodalumab group. Brodalumab was administered either SC (50, 140, and $210 \mathrm{mg}$ each including six patients) or IV (420 and $700 \mathrm{mg}$ each including six patients). The SC doses were administered every 2 weeks, while the IV doses were administered every 4 weeks. Using flow cytometry, total receptor occupancy (RO) was calculated as the proportion of brodalumab bound receptors to total receptors. Placebo patients showed less than 3\% mean IL-17 RO, while brodalumab treatment showed $>95 \%$ IL-17 RO with increases in a dose-dependent manner for all SC and IV treatment groups. Such findings might explain the dose-dependent efficacy of brodalumab in psoriasis patients. ${ }^{24}$

Similarly, Osamu et $\mathrm{al}^{25}$ studied the brodalumab clinical pharmacology via a randomized, dose-escalated, placebo-controlled study. The study population included 40 healthy male volunteers and 13 patients with moderateto-severe psoriasis. It was found that brodalumab PK was nonlinear and similar between healthy individuals and patients with psoriasis. The results demonstrated a parallel rise and decrease in brodalumab serum concentration and IL-17RA occupancy. They identified that $\sim 1 \mu \mathrm{g} / \mathrm{mL}$ brodalumab levels correlated with maximum levels of IL-17 occupancy and that $140 \mathrm{mg}$ dosing every 2 weeks achieves these drug levels. These findings correlate with dosages selected in subsequent efficacy studies.

Another phase 1 randomized placebo-controlled trial by Papp et $\mathrm{al}^{26}$ investigated the clinical response of moderateto-severe psoriasis patients to a single dose of brodalumab. The study included 25 patients, 20 receiving brodalumab and five receiving placebo. The brodalumab treatment group included four patients at $140 \mathrm{mg} \mathrm{SC}$, eight at $350 \mathrm{mg} \mathrm{SC}$, and eight at $740 \mathrm{mg}$ IV. Their findings also confirmed a nonlinear pharmacokinetic profile for brodalumab, with similar parameters between the $700 \mathrm{mg}$ IV group and healthy individuals.

In a phase 2 study by Nakagawa et al, ${ }^{27}$ the steady-state serum concentrations $\left(\mathrm{C}_{\mathrm{ss}}\right)$ were analyzed in a total of
41 patients across the brodalumab $70 \mathrm{mg}$ group (15 patients), $140 \mathrm{mg}$ group (15 patients), and the $210 \mathrm{mg}$ group (11 patients). There was a positive correlation between $\mathrm{C}_{\mathrm{ss}}$ and PASI score percentage improvement.

\section{Potential drug interactions with antidepressants}

Due to concerns about brodalumab possibly causing suicidal ideation and behavior (SIB) events, a potential drug-drug interaction with antidepressants has been explored. However, brodalumab has a low risk for PK drug-drug interactions given that it is eliminated by an extensive reticuloendothelial clearance mechanism. Brodalumab, as a human monoclonal antibody, is catabolized via intracellular mechanisms following phagocytosis and pinocytosis. Subsequently, interactions with the CYP enzymatic metabolism pathway of xenobiotic drugs are highly unlikely.

However, because of brodalumab's unique mechanism of IL-17RA blockade, a dose-dependent increase in serum IL-17A has been observed in clinical studies. Moreover, IL-17A levels are already increased in psoriasis patients compared to healthy individuals. Given that increased levels of inflammatory cytokines are known to alter CYP enzyme functions, it is theoretically plausible that increased serum IL-17A levels in patients treated with brodalumab could lead to increased levels of antidepressants eliminated by the CYP pathway. This notion was supported by a disease-drugdrug interaction study that demonstrated a $24 \%$ increase in midazolam exposure in patients who received a single SC brodalumab dose. Nevertheless, most antidepressants are eliminated by multiple mechanisms, making them unlikely to be susceptible to the theoretical inhibition of a single CYP enzyme pathway. All in all, the observed SIB events in patients on antidepressants are unlikely to be linked to brodalumab drug-drug or disease-drug interactions. ${ }^{28}$

In summary, PK and PD models have demonstrated that brodalumab has a low volume of distribution and slow clearance, similar to other large hydrophilic antibodies with limited tissue penetration. However, multiple simulations based on these models have revealed that TBW is positively correlated with mean population clearance rates. Moreover, data from phase 1 studies suggest that RO increases in a dosedependent manner, regardless of route of administration. In addition, a phase 1 study by Papp et $\mathrm{al}^{26}$ has confirmed a nonlinear pharmacokinetic profile for brodalumab.

\section{Efficacy}

\section{Phase 2 studies}

Several clinical trials have shown that brodalumab is efficacious in the treatment of psoriasis patients (Table 1). The first 
Table I Efficacy studies of brodalumab

\begin{tabular}{|c|c|c|c|c|}
\hline $\begin{array}{l}\text { Indication, } \\
\text { phase of study }\end{array}$ & Study title & $\begin{array}{l}\text { Total number } \\
\text { of patients }\end{array}$ & Dosages studied & Primary results \\
\hline \multirow[t]{4}{*}{$\begin{array}{l}\text { Psoriasis, } \\
\text { phase } 2\end{array}$} & $\begin{array}{l}\text { Brodalumab, an anti- } \\
\text { interleukin- } 17 \text { receptor } \\
\text { antibody for psoriasis }{ }^{29}\end{array}$ & 198 & $\begin{array}{l}\text { Four SC dose cohorts: } 70 \mathrm{mg} \\
(\mathrm{n}=39), 140 \mathrm{mg}(\mathrm{n}=39), 210 \mathrm{mg} \\
(\mathrm{n}=40) \text { on day I and at weeks I, } \\
2,4,6,8 \text {, and } 10 \text {, or } 280 \mathrm{mg} \\
\text { (n=42) on day I and at weeks } 4 \\
\text { and } 8 \\
\text { Matching placebo doses }\end{array}$ & $\begin{array}{l}\text { After I } 2 \text { weeks, the mean PASI score } \\
\text { percentage improvements were } 45.0 \% \text { in the } \\
70 \mathrm{mg} \text { group, } 85.9 \% \text { in the } 140 \mathrm{mg}, 86.3 \% \text { in the } \\
210 \mathrm{mg} \text { group, and } 76.0 \% \text { in the } 280 \mathrm{mg} \text { group } \\
\text { versus } 16.0 \% \text { in the placebo group }\end{array}$ \\
\hline & $\begin{array}{l}\text { Efficacy and safety of } \\
\text { brodalumab in subpopulations } \\
\text { of patients with difficult-to- } \\
\text { treat moderate-to-severe } \\
\text { plaque psoriasis }\end{array}$ & 114 & $\begin{array}{l}\text { I } 40 \text { mg }(n=39) \text { cohort: history } \\
\text { of PsA }(n=11) \text {, no history of } \\
\text { PsA }(n=28) \text {. History of biologic } \\
\text { use }(n=10) \text {, no history of } \\
\text { biologic use }(n=29) \\
210 \text { mg cohort: history of } \\
\text { PsA ( } n=12) \text {, no history of PsA } \\
\text { ( } n=28) . \text { History of biologic use } \\
\text { (n=29), no history of biologic } \\
\text { use }(n=24)\end{array}$ & $\begin{array}{l}\text { PASI } 75,90 \text {, and } 100 \text { response rates, along with } \\
\text { quality-of-life measures were generally similar } \\
\text { between the patient subgroups. Brodalumab } \\
\text { was considered to be still effective in patients } \\
\text { with psoriasis, regardless of their history of } \\
\text { PsA or prior biologic use }\end{array}$ \\
\hline & $\begin{array}{l}\text { Safety and efficacy of } \\
\text { brodalumab for psoriasis after } \\
120 \text { weeks of treatment }{ }^{30}\end{array}$ & 181 & $\begin{array}{l}\text { All received brodalumab } \\
210 \mathrm{mg} \text { Q2W (reduced to } \\
140 \mathrm{mg} \text { for weight of } \leq 100 \mathrm{~kg} \text { ) }\end{array}$ & $\begin{array}{l}\text { sPGA of } 0 \text { or I was achieved by } 90 \% \text { of } \\
\text { patients at week } 12 \text { and } 72 \% \text { of patients at } \\
\text { week } 120 \text {. PASI } 100 \text { response rate was } 63 \% \\
\text { at week } 12 \text { and } 51 \% \text { at week } 120\end{array}$ \\
\hline & $\begin{array}{l}\text { Brodalumab, a human anti- } \\
\text { interleukin- } 17 \text { receptor } \\
\text { antibody in the treatment } \\
\text { of Japanese patients with } \\
\text { moderate-to-severe plaque }\end{array}$ & $|5|$ & $\begin{array}{l}\text { Four SC treatment groups: } \\
70 \mathrm{mg} \text { brodalumab, } 40 \mathrm{mg} \\
\text { brodalumab, } 210 \mathrm{mg} \\
\text { brodalumab, or placebo }\end{array}$ & $\begin{array}{l}\text { After } 12 \text { weeks, the mean percentage } \\
\text { improvements in the PASI scores were } 37.7 \% \\
\text { in the } 70 \mathrm{mg} \text { group, } 82.2 \% \text { in the } 140 \mathrm{mg} \text { group, } \\
96.8 \% \text { in the } 210 \mathrm{mg} \text { group, and } 9.4 \% \text { in the } \\
\text { placebo group }\end{array}$ \\
\hline
\end{tabular}

Psoriasis, A prospective phase 3

phase 3 randomized, double-blind, placebo-controlled study of brodalumab in patients with moderate-to-severe plaque psoriasis $^{32}$

Phase 3 studies comparing brodalumab with ustekinumab in psoriasis ${ }^{33}$
661 in AMAGINE-I

1,831 in AMAGINE-2 AMAGINE-2

\section{Four treatment arms:}

$210 \mathrm{mg}$ brodalumab Q2W, $140 \mathrm{mg}$ brodalumab Q2W, ustekinumab every 12 weeks, and placebo

Three treatment arms: $210 \mathrm{mg}$ brodalumab Q2W, $140 \mathrm{mg}$ brodalumab Q2W, or matching placebo doses

After 12 weeks, $83 \%$ of $210 \mathrm{mg}$ brodalumab group, $60 \%$ of $140 \mathrm{mg}$ group, and $3 \%$ of placebo group achieved PASI $75.76 \%$ of $210 \mathrm{mg}$ brodalumab group, $54 \%$ of $140 \mathrm{mg}$ group, and $1 \%$ of placebo group achieved sPGA 0 or I

After 12 weeks, PASI 75 response rates were $86 \%$ in the $210 \mathrm{mg}$ group, $67 \%$ in the $140 \mathrm{mg}$ group, and $8 \%$ in the placebo group $(P<0.00 \mathrm{I}) .44 \%$ of $210 \mathrm{mg}$ brodalumab group versus $22 \%$ of ustekinumab group achieved PASI 100. However, the PASI 100 response rates in the $140 \mathrm{mg}$ brodalumab group was $26 \%$, not statistically significant compared to ustekinumab $(P=0.08)$. Rates of successful sPGA scores $(0-I)$ were significantly higher with both brodalumab groups (79\% and $58 \%$ ) versus placebo (4\%)

Phase 3 studies comparing $\quad I, 88 \mathrm{I}$ in Same as AMAGINE-2 brodalumab with ustekinumab AMAGINE-3 in psoriasis ${ }^{33}$
After 12 weeks, PASI 75 response rates were $85 \%$ in the $210 \mathrm{mg}$ group, $69 \%$ in the $140 \mathrm{mg}$ group, and $1 \%$ in the placebo group. $37 \%$ of the $210 \mathrm{mg}$ brodalumab group versus $19 \%$ of the ustekinumab group achieved PASI 100. The PASI 100 response rates in the $140 \mathrm{mg}$ brodalumab group was $27 \%(P=0.007)$. Rates of successful sPGA scores $(0-1)$ were significantly higher with both brodalumab groups $(80 \%$ and $60 \%$ ) and placebo (4\%)

Abbreviations: SC, subcutaneous; PASI, Psoriasis Area and Severity Index; sPGA, static physician's global assessment; PsA, psoriatic arthritis; Q2W, every two weeks. 
study was a 2013 randomized, international, double-blind, placebo-controlled, phase 2 trial. ${ }^{29}$ A total of 198 patients were enrolled at multiple international centers. Patients were randomly assigned to receive placebo or brodalumab. Patients assigned to the brodalumab treatment arm received a SC dose of 70, 140, or $210 \mathrm{mg}$ on day 1 and at weeks 1, 2, 4, 6,8 , and 10 or a SC dose of $280 \mathrm{mg}$ on day 1 and at weeks 4 and 8 . The primary treatment end point was PASI percentage improvement 12 weeks after initial treatment. Secondary end points included PASI 75, PASI 90, and static physician's global assessment (sPGA) score at week 12.

After 12 weeks, the mean PASI score percentage improvements were $45.0 \%$ in the $70 \mathrm{mg}$ group, $85.9 \%$ in the $140 \mathrm{mg}$ group, $86.3 \%$ in the $210 \mathrm{mg}$ group, $76.0 \%$ in the $280 \mathrm{mg}$ group, and $16.0 \%$ in the placebo group. In addition, $77 \%$ of the $140 \mathrm{mg}$ group, $82 \%$ of the $210 \mathrm{mg}$ group, and $0 \%$ of the placebo group achieved PASI 75 after 12 weeks. Moreover, $72 \%$ of the $140 \mathrm{mg}$ group, $75 \%$ of the $210 \mathrm{mg}$ group, and $0 \%$ of the placebo group achieved PASI 90. Furthermore, $26 \%$ of the $70 \mathrm{mg}$ group, $85 \%$ of the $140 \mathrm{mg}$ group, $80 \%$ of the $210 \mathrm{mg}$ group, and $69 \%$ of the $280 \mathrm{mg}$ group achieved sPGA scores of 0 or 1 versus $3 \%$ of the placebo group. This phase 2 study demonstrated that brodalumab vastly improved the signs and symptoms of patients with moderate-to-severe plaque psoriasis. ${ }^{29}$

In 2014, an open-label extension study was performed based on the above phase 2 study. ${ }^{30} \mathrm{~A}$ total of 181 patients were enrolled, and all received brodalumab $210 \mathrm{mg}$ every 2 weeks (Q2W). The dose was later reduced to $140 \mathrm{mg}$ with a weight of $\leq 100 \mathrm{~kg}$, but later increased back to $210 \mathrm{mg}$ in patients without adequate responses. Efficacy end points were PASI 75, PASI 90, PASI 100, and sPGA scores. sPGA of 0 or 1 was achieved by $90 \%$ of patients at week 12 and $72 \%$ of patients at week 120 . PASI 100 response rate was $63 \%$ at week 12 and $51 \%$ at 120 weeks. Overall, the efficacy of brodalumab in the treatment of patients with moderateto-severe plaque psoriasis was mostly maintained after 120 weeks. $^{30}$

Papp et $\mathrm{al}^{31}$ performed subset analyses of the abovementioned phase 2 study to assess the efficacy of brodalumab in difficult-to-treat populations of psoriatic patients. The analyses focused on self-reported history of PsA and prior biologic use including anti-TNF agents, ustekinumab, alefacept, and efalizumab. It was found that PASI 75, 90, and 100 response rates, along with quality-of-life measures, were generally similar between the patient subgroups. Thus, it was concluded that brodalumab is still effective in patients with psoriasis regardless of their history of PsA or prior biologic use.
However, this study was limited by the following: PsA was self-reported, reasons for discontinuation of prior biologics were unknown, and many of the subgroups suffered from small sample size as the original study was not designed for subgroup comparison. ${ }^{31}$

Another phase 2 randomized, double-blind, placebocontrolled trial published in 2016 assessed the efficacy of brodalumab in Japanese patients. ${ }^{27}$ A total of 151 patients were randomized into four treatment groups: $70 \mathrm{mg}$ brodalumab, $40 \mathrm{mg}$ brodalumab, $210 \mathrm{mg}$ brodalumab, or placebo. After completing 12 weeks of treatment, patients were permitted to participate in an open-label extension study spanning 1 year. The primary treatment end point was PASI percentage improvement 12 weeks after initial treatment. Secondary end points included PASI 75, 90, 100 after 12 weeks. After 12 weeks, the mean percentage improvements in the PASI scores were $37.7 \%$ in the $70 \mathrm{mg}$ group, $82.2 \%$ in the $140 \mathrm{mg}$ group, $96.8 \%$ in the $210 \mathrm{mg}$ group, and $9.4 \%$ in the placebo group. In addition, $25.6 \%$ of the $70 \mathrm{mg}$ group, $78.4 \%$ of the $140 \mathrm{mg}$ group, $94.6 \%$ of the $210 \mathrm{mg}$ group, and $7.9 \%$ of the placebo group achieved PASI 75. Moreover, $15.4 \%$ of the $70 \mathrm{mg}$ group, $64.9 \%$ of the $140 \mathrm{mg}$ group, $91.9 \%$ of the $210 \mathrm{mg}$ group, and $2.6 \%$ of the placebo group achieved PASI 90. Furthermore, 2.6\% of the $70 \mathrm{mg}$ group, $35.1 \%$ of the $140 \mathrm{mg}$ group, and $59.5 \%$ of the $210 \mathrm{mg}$ group achieved PASI 100 versus $0 \%$ of the placebo group. It was concluded that brodalumab is an efficacious treatment in the Japanese patient population, comparable to previously published studies. ${ }^{27}$

\section{Phase 3 studies}

The AMAGINE-1 trial conducted by Papp et $\mathrm{al}^{32}$ was a randomized, double-blind, phase 3 study comparing brodalumab to placebo. During the 12 -week induction phase, a total of 661 patients were randomized in a 1:1:1 fashion into three treatment arms: $210 \mathrm{mg}$ brodalumab Q2W, $140 \mathrm{mg}$ brodalumab Q2W, or matching placebo doses. At week 12, patients in the brodalumab $210 \mathrm{mg}$ group with sPGA $>2$ were continued on the same treatment, patients with sPGA of 0 or 1 were rerandomized in a 1:1 ratio to brodalumab $210 \mathrm{mg}$ Q2W or placebo. The same design was applied to patients in the brodalumab $140 \mathrm{mg}$ group. Finally, patients receiving placebo during the induction phase were switched to brodalumab $210 \mathrm{mg}$ Q2W. The coprimary end points were PASI 75 response rates and sPGA success (score of 0 or 1 ) at 12 weeks. After 12 weeks of treatment, $83 \%$ of the $210 \mathrm{mg}$ brodalumab group, $60 \%$ of the $140 \mathrm{mg}$ group, and $3 \%$ of the placebo group achieved PASI 75. Similarly, $76 \%$ of the 
$210 \mathrm{mg}$ brodalumab group, $54 \%$ of the $140 \mathrm{mg}$ group, and $1 \%$ of the placebo group achieved sPGA success $(P<0.001$ between brodalumab groups and placebo). ${ }^{32}$

In 2015, Lebwohl et $\mathrm{al}^{33}$ conducted two phase 3 studies (AMAGINE-2 and AMAGINE-3) to compare the efficacy and safety of brodalumab with ustekinumab in patients with moderate-to-severe plaque psoriasis. Both studies had the same design and were randomized, double-blind, placebo-controlled, and active comparator controlled. Both studies were conducted across 142 sites. AMAGINE-2 included 1,831 patients, whereas AMAGINE-3 included 1,881 patients. The two studies comprised of a 12-week induction phase followed by a 40 -week maintenance phase. In the 12-week induction phase, patients were randomized in a 2:2:1:1 ratio into four treatment arms: $210 \mathrm{mg}$ brodalumab, $140 \mathrm{mg}$ brodalumab, ustekinumab, and placebo. For the next 40 weeks, patients who received brodalumab in the induction phase were again rerandomized to four maintenance dose groups: 210 mg Q2W, 140 mg Q2W, 140 mg every 4 weeks, or $140 \mathrm{mg}$ every 8 weeks. Patients receiving ustekinumab during the induction phase continued to receive it every 12 weeks. Finally, patients receiving placebo had their regimen switched to brodalumab every Q2W for the maintenance phase. The primary end points of the studies were to examine, at week 12, brodalumab PASI 75 and sPGA (0-1) compared to placebo and its PASI 100 superiority over ustekinumab.

In the AMAGINE-2 trial, after 12 weeks, PASI 75 response rates were $86 \%$ in the $210 \mathrm{mg}$ group, $67 \%$ in the $140 \mathrm{mg}$ group, and $8 \%$ in the placebo group $(P<0.001)$. Forty-four percent of the $210 \mathrm{mg}$ brodalumab group versus $22 \%$ of the ustekinumab group achieved PASI 100 . However, the PASI 100 response rates in the $140 \mathrm{mg}$ brodalumab group was $26 \%$, not statistically significantly better than ustekinumab $(P=0.08)$. Rates of sPGA scores of $0-1$ were significantly higher with both brodalumab groups (79\% and $58 \%$ with brodalumab 210 and $140 \mathrm{mg}$, respectively) versus placebo (4\%).

In the AMAGINE-3 trial, after 12 weeks, PASI 75 response rates were $85 \%$ in the $210 \mathrm{mg}$ group, $69 \%$ in the $140 \mathrm{mg}$ group, and $1 \%$ in the placebo group. Thirty-seven percent of the $210 \mathrm{mg}$ brodalumab group versus $19 \%$ of the ustekinumab group achieved PASI $100(P<0.001)$. The PASI 100 response rates in the $140 \mathrm{mg}$ brodalumab group was $27 \%$ ( $P=0.007$ for comparison with ustekinumab group). Rates of sPGA scores 0 to 1 were significantly higher with both brodalumab groups (80\% and $60 \%$, with brodalumab 210 and $140 \mathrm{mg}$, respectively) versus placebo $(4 \%) .{ }^{33}$

\section{Safety and tolerability}

The main adverse events from the induction phases (through 12 weeks) of all three phase 3 AMAGINE trials are summarized in Table 2 and categorized into serious, fatal, depression, serious infectious episodes, major adverse cardiac events (MACE), neutropenia, Candida episodes, and common adverse events. Selected exposure-adjusted adverse events through 52 weeks of treatment are compared among the AMAGINE trials (Table 3) and include serious, fatal, MACE, suicide attempts/ideation/completed events, neutropenia, and Candida episodes.

\section{Neutropenia and candidiasis}

It is known that IL-17A plays a key role in stimulation of granulopoiesis and neutrophil trafficking. ${ }^{34,35}$ Thus, when administering brodalumab to patients, neutropenia is an important adverse effect that must be monitored. In the AMAGINE-1 trial induction phase, one case of neutropenia occurred in the $140 \mathrm{mg}$ treatment group. ${ }^{32}$ The exposureadjusted event rate through 52 weeks was 0.4 events per 100 patient-years (Table 3). All cases were grade 1 or 2, resolved spontaneously, and were not associated with infection. ${ }^{32}$ In the induction phases of the AMAGINE-2 and AMAGINE-3 trials, neutropenia events were higher in the brodalumab and ustekinumab groups compared to placebo (Table 2). The brodalumab exposure-adjusted event rates per 100 patient-years through 52 weeks were 0.2 in the AMAGINE-2 trial and 1.5 in the AMAGINE-3 trial. Similar to the AMAGINE-1 trial, most of the cases were mild and reversible. ${ }^{33}$ No cases of grade 3 or 4 neutropenia were reported in any of the AMAGINE trials.

Th17 cells, and IL-17A in particular, are important in host defense of skin and mucous membranes against bacteria and fungi. ${ }^{36-38}$ More specifically, one study found that murine (m) IL-17A receptor knockout mice had significantly decreased survival when exposed to Candida albicans compared to healthy wild-type mice. ${ }^{38}$ This finding may explain why Candida infections occurred more frequently in brodalumabtreated patients in the AMAGINE trials (Tables 2 and 3). Of note, all Candida infections were mild to moderate and none were systemic. ${ }^{32,33}$ Continued vigilance with regard to potential Candida infection will be essential for brodalumab and other IL-17A inhibitors.

\section{Suicidal ideation and behavior (SIB) events}

A substantial number of dermatological conditions are complicated by psychological and psychiatric features. ${ }^{39}$ The rates of psychiatric disorders in psoriasis patients are similar to those 


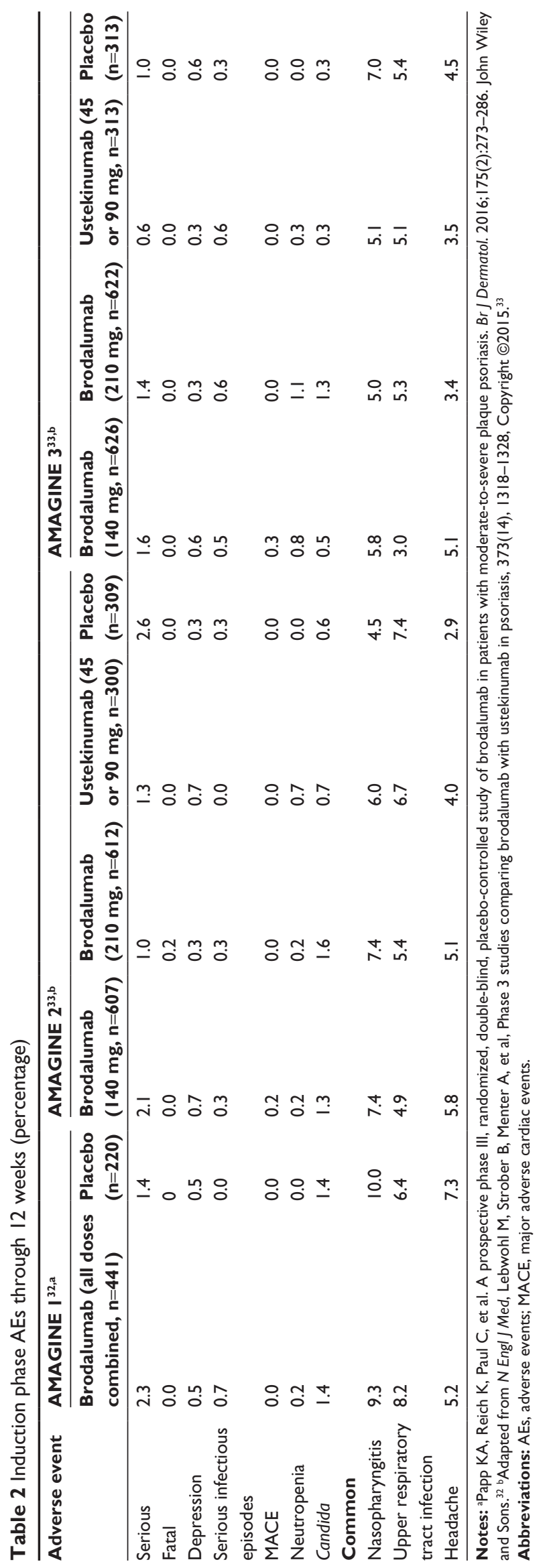

seen in vitiligo, eczema, acne, and pemphigus patients..$^{40-42}$ The impaired quality of life of these patients secondary to skin disfigurement is one explanation for the high rate of psychological distress. ${ }^{40}$ The biological impact of psoriasis on the sympathetic nervous system and hypothalamic-pituitaryadrenal axis may be another explanation for the association of this disease with psychiatric and mood disorders. ${ }^{43}$

SIB events have been reported in phase 2 and 3 clinical studies involving brodalumab treatment of psoriasis, PsA, and asthma. A total of 6,243 patients, accounting for 10,438 patient-years of exposure, were followed from their first brodalumab dose to the end of the study. The SIB events included six completed suicides (four in psoriasis patients), eleven suicide attempts (ten in psoriasis patients) compared to two in the ustekinumab groups, and 24 reports of suicidal ideation (22 in psoriasis patients and two in placebo patients in an asthma study). ${ }^{28}$

The drug sponsor subsequently analyzed pooled data from the psoriasis patient subset treated with brodalumab. The patient-years were calculated based on the total number of patients who received at least one dose of brodalumab in the phase 2 studies and the three AMAGINE trials. Two patient pools were then created based on the length of treatment: a 52-week and a long-term pool. In the 52-week pool, the SIB exposure-adjusted incidence rates were $0.40(95 \%$ CI: $0.05-1.46)$ per 100 patient-years in the ustekinumabtreated patients ( $\mathrm{n}=613$ patients, 494 patient-years) compared to 0.17 (95\% CI: 0.06-0.38) per 100 patient-years in brodalumab-treated patients $(\mathrm{n}=4,019$ patients, 3,444 patientyears). In the long-term patient pool, which included data through the end of the brodalumab trials, the SIB exposureadjusted incidence rate was 0.28 (95\% CI: $0.18-0.41)$ per 100 patient-years among all patients treated with brodalumab $(\mathrm{n}=4,464$ patients, 8,647 patient-years $) .^{28}$

While the majority of SIB events occurred in brodalumab psoriasis studies, it is important to note that psoriasis patients with a previous history of psychiatric or substance use disorders were not excluded from the Papp et al phase 2 study or the phase 3 AMAGINE trials. ${ }^{28,29}$ A subsequent subgroup analysis performed by the FDA Division of Biometrics 7 (DB7) demonstrated that brodalumab-treated patients with baseline depression or suicidality had a 7 - and $12-18$-fold increase, respectively, in SIB incidence rates versus patients without such histories. A similar pattern was identified in the FDA Division of Pharmacovigilance (DPV) analysis of neuropsychiatric adverse events in psoriasis studies. ${ }^{44,45}$

When comparing SIB data in brodalumab psoriasis clinical trials to data from other psoriasis biologics, the FDA 
Table 3 Exposure-adjusted AEs through week 52 (event rate per 100 patient-years)

\begin{tabular}{|c|c|c|c|c|c|}
\hline \multirow[t]{2}{*}{ Adverse event } & \multirow{2}{*}{$\frac{\text { AMAGINE I }}{\text { Brodalumab }}$} & \multicolumn{2}{|c|}{ AMAGINE $2^{33, b}$} & \multicolumn{2}{|c|}{ AMAGINE $3^{33, \mathrm{~b}}$} \\
\hline & & Brodalumab & Ustekinumab & Brodalumab & Ustekinumab \\
\hline Serious* & 9.5 & 8.3 & 13 & 7.9 & 4.0 \\
\hline Fatal & 0.8 & 0.1 & 0.8 & 0.1 & 0.0 \\
\hline MACE*** & 1.0 & 0.4 & 0.8 & 0.7 & 0.0 \\
\hline Depression & 1.2 & 1.7 & 3.3 & 1.8 & 0.8 \\
\hline Suicide attempt & $0.0 * * *$ & 0.2 & 0.4 & 0.0 & 0.0 \\
\hline Suicidal ideation & $0.0 * * *$ & 0.1 & 0.0 & 0.1 & 0.4 \\
\hline Serious infectious episodes & 1.8 & 1.0 & 0.8 & 1.3 & 1.2 \\
\hline Completed suicide & $0.2^{* * * *}$ & $0.1 * * *$ & 0.0 & 0.0 & 0.0 \\
\hline Neutropenia & 0.4 & 0.2 & 0.8 & 1.5 & 0.8 \\
\hline Candida & 3.5 & 4.1 & 5.2 & 5.7 & 1.6 \\
\hline
\end{tabular}

Notes: *A serious adverse event was defined as an event that was fatal or life-threatening, led to inpatient hospitalization or prolongation of existing hospitalization, caused persistent or substantial disability or incapacity, caused a congenital anomaly or birth defect, or was considered by the investigator to be medically important. **Was

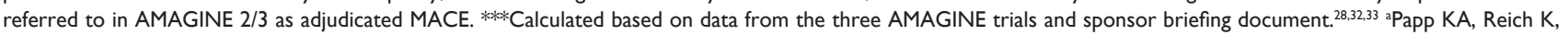
Paul C, et al. A prospective phase III, randomized, double-blind, placebo-controlled study of brodalumab in patients with moderate-to-severe plaque psoriasis. Br J Dermatol. 2016; I75(2):273-286. John Wiley and Sons. ${ }^{32}$ bAdapted from N Engl J Med, Lebwohl M, Strober B, Menter A, et al, Phase 3 studies comparing brodalumab with ustekinumab in psoriasis, 373(14), 1318-1328, Copyright (2015. ${ }^{33}$

Abbreviations: AEs, adverse events; MACE, major adverse cardiac events.

Division of Epidemiology (DEPI) found that the suicide rate (adjusted per 100,000 patient-years) was three to four times higher in the brodalumab trials. Limitations of this data pooling analysis included time restraints and limited safety data of some of the medications studied ${ }^{44,45}$ In addition, the incidence of baseline psychiatric conditions in brodalumabtreated patients compared to that of patients treated with other psoriasis biologics is unknown.

On the other hand, brodalumab appeared to have a positive effect on depression and anxiety symptoms based on implementation of the Hospital Anxiety-Depression Scale in the AMAGINE-1 trial. In a relatively small sample group, it was found that patients with baseline depression and anxiety symptoms in the brodalumab arm showed higher levels of improvements in their psychiatric symptoms compared to similar patients in the placebo group. ${ }^{32}$ However, an improvement in skin symptoms and quality of life could possibly account for the observed results.

The DPV, DEPI, and Division of Psychiatry Products (DPP) stated that based on the available data, no conclusions can be drawn regarding suicidality and whether or not it is a drug-related risk. The role, if any, that brodalumab has in causing the observed suicides is difficult to assess given the fact that psoriasis patients have a baseline-increased rate of SIB. Moreover, case information from the six completed suicides was limited, and three of the patients committed suicide more than 19 days after their last brodalumab dose. That being said, suicide and SIB events in general are still potential risks associated with brodalumab treatment. Risk-mitigation strategies, including use of the electronic Columbia-Suicide Severity Rating Scale (eC-SSRS) and the Patient Health Questionnaire-8 (PHQ-8), have been used by the drug sponsor to monitor patients for signs of depression and suicidality. However, these tools are not completely reliable as some patients can develop SIB after a negative screen. ${ }^{44}{ }^{46}$ Postmarketing surveillance will be difficult given that health care claims/administrative data do not reliably document SIB events. ${ }^{46}$ With FDA approval of brodalumab, in addition to a black box warning of the risks of SIB, the FDA has required the use of a Risk Evaluation and Mitigation Strategy (REMS) to ensure that prescribers and patients are vigilant for SIB. ${ }^{5}$

\section{Inflammatory bowel disease}

A phase 2 study assessed the efficacy and safety of brodalumab in patients with active moderate-to-severe Crohn's disease. ${ }^{47}$ The primary end point was achievement of Crohn's disease activity index (CDAI) remission at week 6 . However, none of the brodalumab treatment groups $(210,350$, and $700 \mathrm{mg}$ IV doses) demonstrated any clinically significant efficacy. Furthermore, the study was terminated early due to a substantial number of patients in the treatment groups experiencing worsening of their Crohn's disease symptoms. ${ }^{47}$

Based on the findings of the previous study, any patients with a known history of Crohn's disease were excluded from the phase 2 and 3 brodalumab psoriasis clinical trials. There were a total of six cases of enteritis in the brodalumab treatment groups across all the trials. Of note, there was one case of new-onset Crohn's disease during the maintenance phase of the AMAGINE-2 trial, and this patient was subsequently withdrawn from the study. As a result, the sponsor has included drug labeling explicitly stating that brodalumab is contraindicated in patients with active or previous Crohn's disease. ${ }^{44,45}$ 
IBD-related adverse effects have also been reported with two other current IL-17 inhibitors: secukinumab and ixekizumab. In a phase 2 trial involving patients with moderate-to-severe Crohn's disease, secukinumab treatment was not effective and resulted in higher adverse events, including infection and worsening of Crohn's disease, compared to placebo. ${ }^{48}$ Moreover, exacerbations of existing Crohn's disease and a new case of Crohn's disease have been reported in secukinumab phase 3 trials. ${ }^{49}$ Similarly, during the induction phases of placebo-controlled trials, there has been a greater frequency of Crohn's and ulcerative colitis exacerbations in ixekizumab treatment groups. ${ }^{50}$ As such, both of these medications contain labels stating that patients with IBD should be monitored closely..$^{49,50}$

\section{Considerations for the future}

Brodalumab provides another IL-17 inhibitor treatment option for psoriasis alongside ixekizumab and secukinumab. Future studies involving brodalumab in combination with other treatment modalities may be warranted for resistant psoriasis cases that failed to respond to a single agent. Concerning PsA, one phase 2 study has demonstrated moderate improvements in American College of Rheumatology (ACR) 20 and ACR50 response rates with brodalumab treatment. ${ }^{51}$ However, more clinical trials will be necessary to determine the efficacy of brodalumab in treating PsA. Future pharmacovigilance studies will also be important to assess the longterm efficacy of brodalumab in treating psoriasis, its potential place in therapy, and the long-term risks of brodalumab.

\section{Conclusion}

Brodalumab is a new IL-17RA human monoclonal antibody inhibitor that has been FDA approved for the treatment of moderate-to-severe plaque psoriasis. In contrast to other FDAapproved IL-17A inhibitors, secukinumab and ixekizumab, brodalumab targets the IL-17A receptor. PASI 75, PASI 100, and sPGA 0 or 1 response rates of brodalumab appear comparable to those of ixekizumab and secukinumab. ${ }^{44}$

Studies have also revealed adverse effects and potential safety concerns with brodalumab administration. Given that brodalumab targets the IL-17 pathway, patients should be monitored for neutropenia and Candida infections. With regard to IBD, brodalumab, as well as ixekizumab and secukinumab, was ineffective as a treatment modality and resulted in exacerbations. As such, ixekizumab and secukinumab labels include warning that IBD patients taking these medications should be monitored closely. FDA approval for brodalumab also included a label with a similar warning. ${ }^{45}$
The most serious potential safety concern with brodalumab treatment is the development of SIB. No plausible causal relationship has been established between brodalumab treatment and the suicides that occurred during clinical trials. ${ }^{44}$ This will likely continue to be a topic of debate, and new studies may be necessary to adequately assess the risk of suicidality.

\section{Disclosure}

The authors report no conflicts of interest in this work.

\section{References}

1. Gelfand JM, Weinstein R, Porter SB, Neimann AL, Berlin JA, Margolis DJ. Prevalence and treatment of psoriasis in the United Kingdom: a population-based study. Arch Dermatol. 2005;141(12): $1537-1541$.

2. Rachakonda TD, Schupp CW, Armstrong AW. Psoriasis prevalence among adults in the United States. J Am Acad Dermatol. 2014;70(3): 512-516.

3. Augustin M, Radtke MA. Quality of life in psoriasis patients. Expert Rev Pharmacoecon Outcomes Res. 2014;14(4):559-568.

4. Wasilewska A, Winiarska M, Olszewska M, Rudnicka L. Interleukin-17 inhibitors. A new era in treatment of psoriasis and other skin diseases. Postepy Dermatol Alergol. 2016;33(4):247-252.

5. Abuhilal M, Walsh S, Shear N. The role of IL-17 in the pathogenesis of psoriasis and update on IL-17 inhibitors for the treatment of plaque psoriasis. J Cutan Med Surg. 2016;20(6):509-516.

6. US Food and Drug Administration [webpage on the Internet]. FDA Approves New Psoriasis Drug. Available from: https://www.fda. gov/NewsEvents/Newsroom/PressAnnouncements/ucm541981.htm. Accessed February 19, 2017.

7. Greig SL. Brodalumab: first global approval. Drugs. 2016;76(14): 1403-1412.

8. Bauer E, Lucier J, Furst DE. Brodalumab - an IL-17RA monoclonal antibody for psoriasis and psoriatic arthritis. Expert Opin Biol Ther. 2015;15(6):883-893.

9. Nestle FO, Kaplan DH, Barker J. Psoriasis. N Engl J Med. 2009; 361(5):496-509.

10. Cai Y, Fleming C, Yan J. New insights of T cells in the patho-genesis of psoriasis. Cell Mol Immunol. 2012;9(4):302-309.

11. Lønnberg AS, Zachariae C, Skov L. Targeting of interleukin-17 in the treatment of psoriasis. Clin Cosmet Investig Dermatol. 2014;7:251-259.

12. Boehncke WH. Etiology and pathogenesis of psoriasis. Rheum Dis Clin North Am. 2015;41(4):665-675.

13. Lynde CW, Poulin Y, Vender R, Bourcier M, Khalil S. Interleukin 17A: toward a new understanding of psoriasis pathogenesis. $J$ Am Acad Dermatol. 2014;71(1):141-150.

14. Lowes MA, Kikuchi T, Fuentes-Duculan J, et al. Psoriasis vulgaris lesions contain discrete populations of Th1 and Th17 T-cells. J Invest Dermatol. 2008;128(5):1207-1211.

15. Numasaki M, Fukushi J, Ono M, et al. Interleukin-17 promotes angiogenesis and tumor growth. Blood. 2003;101(7):2620-2627.

16. Gaffen SL. Structure and signalling in the IL-17 receptor family. Nat Rev Immunol. 2009;9(8):556-567.

17. Iwakura $Y$, Ishigame H, Saijo S, Nakae S. Functional specialization of interleukin-17 family members. Immunity. 2011;34(2):149-162.

18. Chang SH, Dong C. Signaling of interleukin-17 family cytokines in immunity and inflammation. Cell Signal. 2011;23(7):1069-1075.

19. Coimbra S, Figueiredo A, Santos-Silva A. Brodalumab: an evidencebased review of its potential in the treatment of moderate-to-severe psoriasis. Core Evid. 2014;9:89-97.

20. Nirula A, Nilsen J, Klekotka P, et al. Effect of IL-17 receptor A blockade with brodalumab in inflammatory diseases. Rheumatology (Oxford). 2016;55(suppl 2):ii43-ii55. 
21. Russell CB, Rand H, Bigler J, et al. Gene expression profiles normalized in psoriatic skin by treatment with brodalumab, a human anti-IL-17 receptor monoclonal antibody. J Immunol. 2014;192(8):3828-3836.

22. Salinger DH, Endres CJ, Martin DA, Gibbs MA. A semi-mechanistic model to characterize the pharmacokinetics and pharmacodynamics of brodalumab in healthy volunteers and subjects with psoriasis in a first-in-human single ascending dose study. Clin Pharmacol Drug Dev. 2014;3(4):276-283.

23. Endres CJ, Salinger DH, Köck K, et al. Population pharmacokinetics of brodalumab in healthy adults and adults with psoriasis from single and multiple dose studies. J Clin Pharmacol. 2014;54(11):1230-1238.

24. Martin DA, Churchill M, Flores-suarez L, et al. A phase Ib multiple ascending dose study evaluating safety, pharmacokinetics, and early clinical response of brodalumab, a human anti-IL-17R antibody, in methotrexate-resistant rheumatoid arthritis. Arthritis Res Ther. 2013; 15(5):R164.

25. Osamu N, Hirotaka N, Koji S, Kenji T. Clinical pharmacology of the anti-IL-17 receptor antibody brodalumab (KHK4827) in Japanese normal healthy volunteers and Japanese subjects with moderate to severe psoriasis: a randomized, dose-escalation, placebo-controlled study. J Dermatol Sci. 2014;75(3):201-204.

26. Papp KA, Reid C, Foley P, et al. Anti-IL-17 receptor antibody AMG 827 leads to rapid clinical response in subjects with moderate to severe psoriasis: results from a phase I, randomized, placebo-controlled trial. J Invest Dermatol. 2012;132(10):2466-2469.

27. Nakagawa H, Niiro H, Ootaki K; Japanese Brodalumab Study Group. Brodalumab, a human anti-interleukin-17-receptor antibody in the treatment of Japanese patients with moderate-to-severe plaque psoriasis: efficacy and safety results from a phase II randomized controlled study. J Dermatol Sci. 2016;81(1):44-52.

28. Sponsor Briefing Document. BRODALUMAB Injection. Available from: http://www.fda.gov/downloads/AdvisoryCommittees/Committees MeetingMaterials/Drugs/DermatologicandOphthalmicDrugsAdvisory Committee/UCM511360.pdf. Accessed December 2, 2016.

29. Papp KA, Leonardi C, Menter A, et al. Brodalumab, an anti-interleukin17-receptor antibody for psoriasis. N Engl J Med. 2012;366(13): 1181-1189.

30. Papp K, Leonardi C, Menter A, et al. Safety and efficacy of brodalumab for psoriasis after 120 weeks of treatment. J Am Acad Dermatol. 2014; 71(6):1183-1190.e3.

31. Papp K, Menter A, Strober B, et al. Efficacy and safety of brodalumab in subpopulations of patients with difficult-to-treat moderate-to-severe plaque psoriasis. J Am Acad Dermatol. 2015;72(3):436-439.e1.

32. Papp KA, Reich K, Paul C, et al. A prospective phase III, randomized, double-blind, placebo-controlled study of brodalumab in patients with moderate-to-severe plaque psoriasis. Br J Dermatol. 2016;175(2): 273-286.

33. Lebwohl M, Strober B, Menter A, et al. Phase 3 studies comparing brodalumab with ustekinumab in psoriasis. NEngl J Med. 2015;373(14): 1318-1328.

34. Ley K, Smith E, Stark MA. IL-17A-producing neutrophil-regulatory Tn lymphocytes. Immunol Res. 2006;34(3):229-242.

35. Schwarzenberger P, La Russa V, Miller A, et al. IL-17 stimulates granulopoiesis in mice: use of an alternate, novel gene therapy-derived method for in vivo evaluation of cytokines. J Immunol. 1998;161(11): 6383-6389.
36. Iwakura Y, Nakae S, Saijo S, Ishigame H. The roles of IL-17A in inflammatory immune responses and host defense against pathogens. Immunol Rev. 2008;226:57-79.

37. Matsuzaki G, Umemura M. Interleukin-17 as an effector molecule of innate and acquired immunity against infections. Microbiol Immunol. 2007;51(12):1139-1147.

38. Huang W, Na L, Fidel PL, Schwarzenberger P. Requirement of interleukin-17A for systemic anti-Candida albicans host defense in mice. J Infect Dis. 2004;190(3):624-631.

39. Gupta MA, Gupta AK. Psychiatric and psychological co-morbidity in patients with dermatologic disorders, epidemiology and management. Am J Clin Dermatol. 2003;4(12):833-842.

40. Kumar V, Mattoo SK, Handa S. Psychiatric morbidity in pemphigus and psoriasis: a comparative study from India. Asian J Psychiatr. 2013;6(2): 151-156.

41. Sharma N, Koranne RV, Singh RK. Psychiatric morbidity in psoriasis and vitiligo: a comparative study. J Dermatol. 2001;28(8):419-423.

42. Mufaddel A, Abdelgani AE. Psychiatric comorbidity in patients with psoriasis, vitiligo, acne, eczema and group of patients with miscellaneous dermatological diagnoses. Open J Psychiatry. 2014;4(3):168-175.

43. Connor CJ, Liu V, Fiedorowicz JG. Exploring the physiological link between psoriasis and mood disorders. Dermatol Res Pract. 2015; 2015:409637.

44. FDA. Background Package for BLA 761032 Siliq (Brodalumab) Injection, $210 \mathrm{mg} / 1.5 \mathrm{ml}$. Available from: http:/www.fda.gov/downloads/ AdvisoryCommittees/CommitteesMeetingMaterials/Drugs/Dermat ologicandOphthalmicDrugsAdvisoryCommittee/UCM511357.pdf. Accessed November 30, 2016.

45. Highlights of Prescribing Information [Revised February, 2017]. Available from https://www.accessdata.fda.gov/drugsatfda_docs/ label/2017/761032lbl.pdf. Accessed February 21, 2017.

46. Walkup JT, Townsend L, Crystal S, Olfson M. A systematic review of validated methods for identifying suicide or suicidal ideation using administrative or claims data. Pharmacoepidemiol Drug Saf. 2012; 21(S1):174-182.

47. Targan SR, Feagan B, Vermeire S, et al. A randomized, double-blind, placebo-controlled phase 2 study of brodalumab in patients with moderate-to-severe Crohn's disease. Am J Gastroenterol. 2016;111(11): 1599-1607.

48. Hueber W, Sands BE, Lewitzky S, et al. Secukinumab, a human antiIL-17A monoclonal antibody, for moderate to severe Crohn's disease: unexpected results of a randomised, double-blind placebo-controlled trial. Gut. 2012;61(12):1693-1700.

49. Highlights of Prescribing Information [Revised January 1, 2016]. Available from: http://www.pharma.us.novartis.com/product/pi/pdf/ cosentyx.pdf. Accessed January 6, 2017.

50. Highlights of Prescribing Information [Revised March 3, 2016]. Available from: http://pi.lilly.com/us/taltz-uspi.pdf. Accessed January 6, 2017.

51. Mease PJ, Genovese MC, Greenwald MW, et al. Brodalumab, an antiIL17RA monoclonal antibody, in psoriatic arthritis. $N$ Engl J Med. 2014;370(24):2295-2306.

\section{Publish your work in this journal}

Drug Design, Development and Therapy is an international, peerreviewed open-access journal that spans the spectrum of drug design and development through to clinical applications. Clinical outcomes, patient safety, and programs for the development and effective, safe, and sustained use of medicines are the features of the journal, which

\section{Dovepress}

has also been accepted for indexing on PubMed Central. The manuscript management system is completely online and includes a very quick and fair peer-review system, which is all easy to use. Visit http://www.dovepress.com/testimonials.php to read real quotes from published authors. 